\title{
Decorative elements in muslim fashion product: A case study using macrame technique
}

\author{
C. Puspitasari \\ Universiti Sains Malaysia, Penang, Malaysia
}

A.S. Pakpahan

Telkom University, Bandung, Indonesia

J. Dolah

Universiti Sains Malaysia, Malaysia

S. Yuningsih

Telkom University, Bandung, Indonesia

\begin{abstract}
The research's problem is the limitation in using structure design techniques, especially macrame in Muslim fashion. Based on the observation and interview, decorative elements in Muslim fashion dominated by surface textile techniques, such as embroidery, both by machine or hand embroidery and beads embellishment. Whereas, besides there are opportunities for structural textile design applied to Muslim fashion as decorative elements. The previous study used basic knot patterns and minimal exploration of its concepts, shapes, materials, and color combination. This research aims to develop a decorative element in Muslim fashion products by utilizing the potential of macrame. The experiments were carried out in stages, including the macrame knot pattern experiment and the 3D module experiment using the macrame technique. This study's output is the implementation of Macrame experiments on Muslim fashion products, which could be a reference for further Muslim fashion research.
\end{abstract}

Keywords: Decorative Element, Macrame, Muslim Fashion, Structure Textile

\section{INTRODUCTION}

The development of Muslim fashion trends in Indonesia increased significantly due to several things: developing technology and information, the growth of the Islamic community, and the rise of Muslim fashion shows and trade exhibitions (Puspitasari \& Dolah 2017). Other than that, Hijrah's phenomenon on Indonesian Muslim - celebrities since 2018 has played a role in increasing people's interest in Muslim fashion and wearing fashionable products. (Puspitasari \& Dolah 2018).

For those people who work in fashion design, to answer the potential things of this phenomenon, they need to be creative and innovative (Fan \& Zhou 2020). Therefore, in the opportunity to offer alternative designs in Muslim fashion products. The decoration on fashion makes fashion development more dynamic, considering the silhouette or design of the basic forms of fashion generally does not change at once but evolves gradually from one to another through changes in detail (Udale 2014). Decorative elements can function as an effort to improve the quality and attractiveness of a product. Based on the previous study, the decorative elements in Indonesian Muslim fashion products most widely use the surface technique textile, such as painting, embroidery, and beads embellishment (Puspitasari et al. 2019).

Macrame, one kind of structure textile technique, is not common in Muslim fashion, but it can actually be applied as decorative elements. This is because the macrame technique's basic knot patterns can be combined and modified so it can produce an unlimited variety of knot shapes (Rizani 2018). 


\section{METHOD}

Based on the design process, there are three steps, as shown in the research method phase (Wang et al. 2013)

1. Identification: in this stage, extracting features from an original object,

2. Translation: in this stage, transforming object elements into design elements, principles, technique

3. Implementation: in the last stage, designing the product

\subsection{Data collection}

The data collection method in this study is observation and experiment. Through the direct field observation method to the Muslim fashion events or Muslim market place in Indonesia both online and on-site, the focus was on how decorative elements in Muslim fashion products were made. Using visual references to generate ideas is a way to get source information, and it is not the same as copying. It is important to take the information and develop and transform it (Purcell 2005). Based on the Hijrah phenomenon, Muslim celebrities and Indonesian Muslim fashion designers play a role in increasing public interest in using fashionable products. Therefore, the design process begins with the determination of fashion icons and determining the inspiration derived from the form of flower (Gaimster 2011). The determination of the inspiration at this stage is based on observations made other than that flower has a symbolic and meaningful relation to the women (Brown 2020). Another data collection method in this study is the experiment. The experiment gained data about the knot variation for decorative elements that appropriate with the objective of this study to offer an alternative design of decorative elements in Muslim fashion products.

\subsection{Data analysis}

To analyze the data, this study used a sample of macrame technique experimental results and combined it with the composition of the placement of decorative elements in Muslim fashion products.

\section{RESULT AND DISCUSSION}

\subsection{The analysis of decorative elements in Muslim fashion product using macrame technique}
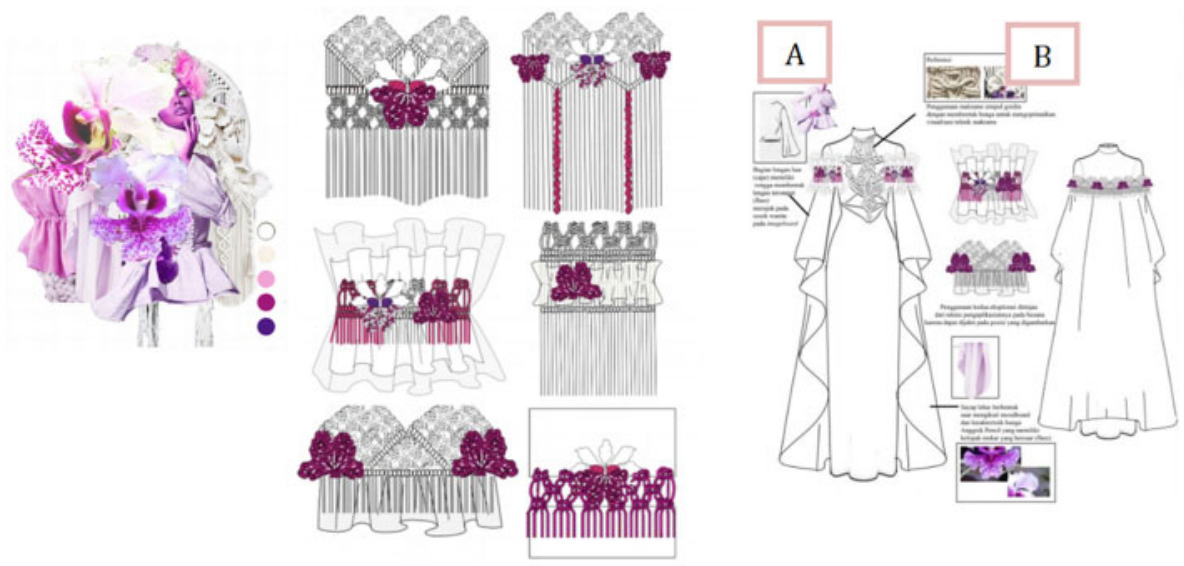

Figure 1. The stages of experiment - macrame application in Muslim fashion product. 
From the experiments conducted, it was found that the combination of several basic macrame knots can produce new shape variations. The figure above showed the result of macramé application in Muslim Fashion products. Starting in the IDENTIFICATION stage, using visual inspiration in the form of a mood board containing a collection of picture collages consisting of pencil orchids, basic macrame patterns, and fashion icons related to the product(A). Then, for the TRANSLATION stage (B), adapting the idea from the mood board and transforming it into a fabric experiment sheet. The macramé experiment was carried out in two stages, starting from making an exploration using basic macrame, then doing 3D modules, and making the combined 3D modules' combined composition. After getting the fabric composition containing the macramé technique, the IMPLEMENTATION stage (C) applies it to the Muslim fashion product.

The macramé technique is a structured textile that requires the maker or the designer; therefore, the determination of Muslim fashion products must be following the experimental stage's efforts and the character of the experimental results themselves. Also, based on the observations made, it was concluded that the type of Muslim fashion products that are suitable for the experiment results is a party dress. The form of clothing is a dress with a basic A-line shape with a decorative macramé element as the center of attention. The macrame experiment's fabric is treated in a similar way to the lace that generally dangles over the clothing. Then the 3D module, which has the form of an orchid, was repetitively applied so that a harmonious and orderly composition of decorative elements was obtained.

Overall, after adding decorative elements, the dress has a Y silhouette where the top looks wider, and the lower part looks smaller. This is due to the addition of a robe inspired by the shape of orchid flower petals. On the body part of the dress is presented a tube shape based on a pencil's shape. According to the pencil orchid flowers, the color shades used in the dress are mostly white and purple gradations. The composition of the color between the dress and the macrame's decorative elements is used as accents in the outfit. This outfit also has asymmetrical balance in terms of distance and layout from the left and left sides.

\section{CONCLUSION}

This research discusses the macrame technique's advantages to create an alternative decorative element design for Muslim fashion. Based on the process, it can be concluded that the pattern structure and aesthetic impression formed from the composition of the experimental results on the product are proof that gradually through the process of identification, transformation, and implementation, the design process that occurs will be clear and directed.

Based on observations and experiments that have been carried out in this study, the macrame technique is included in the slow design technique because it requires good skills to produce explorative modules and sheets. Therefore, the appropriate types of Muslim fashion products following this character are the clothes aimed at special events. This is in line with the value of textile craftsmanship, which wants to expose.

Design concepts can support optimization macramé as a technique to make a decorative element in Muslim fashion. In this research, the concept is carried out in Indonesia's local content, namely the Pencil Orchid flower. This flower is an endemic flora of Indonesia and can function as an inspiration because a macrame combination knot pattern can form its appearance and physique. This inspiration is related to the segmentation of Muslim fashion products that are made, namely women with grace and femininity.

For further studies, some opportunities can be developed. In this study, the macrame technique was applied as a decorative element in Muslim fashion products, and the portion amount was less than $50 \%$. In the next study, it can make product development using the macrame technique with more than $50 \%$. Also, using other concepts besides flowers will be able to produce more varied designs. 


\section{ACKNOWLEDGEMENT}

I gratefully acknowledge the support for this research provided by School of the Creative Industries, Telkom University and School of the Art, Universiti Sains Malaysia. The author also wishes to thank all colleagues in the Textile \& Fashion Department, Telkom University who have contributed to this study. Thank you for all the support.

\section{REFERENCES}

Brown, M. L. (2020). Representing the Modified Body. In In The International Encyclopedia of Gender, Media, and Communication (eds K. Ross, I. Bachmann, V. Cardo, S. Moorti and M. Scarcelli). https://doi.org/doi:10.1002/9781119429128.iegmc310

Fan, K. K., \& Zhou, Y. (2020). The influence of traditional cultural resources (TCRs) on the communication of clothing brands. Sustainability (Switzerland), 12(6), 1-19. https://doi.org/10.3390/su12062379

Gaimster, J. (2011). Visual Research Methods in Fashion. Berg Publisher.

Purcell, P. (2005). How designers think. In Design Studies (Vol. 2). https://doi.org/10.1016/0142694x(81)90033-8

Puspitasari, C., \& Dolah, J. (2017). Hijab Design and Style in Indonesia which Influenced by. SSPIS 2017 Proceedings, 201-212. Retrieved from http://eprints.usm.my/40509/1/ART_27.pdf

Puspitasari, C., \& Dolah, J. (2018). The Analysis of Integration between Hijab Concept and Fashion in Indonesia. Proceedings of the 3rd International Conference on Creative Media, Design and Technology (REKA 2018), 325-328. https://doi.org/https://doi.org/10.2991/reka-18.2018.71

Puspitasari, C., Wulan, D. A., \& Dolah, J. (2019). Designing “ Culture " Into Modern Product - A Case Study Of Bengkulu ' $S$ Ark Festival As An Inspiration In Muslim Fashion Product. Proceeding of the International Conference on Local Knowledge (ICLK) 2019, 1-4. Kuala Lumpur: USM.

Rizani, H. (2018). Aplikasi teknik makrame pada produk aksesoris fesyen untuk remaja perempuan (Telkom University). Retrieved from https://openlibrary.telkomuniversity.ac.id/home/catalog/id/147623/slug/aplikasiteknik-makrame-pada-produk-aksesoris-fesyen-untuk-remaja-perempuan.html

Udale, J. (2014). Basic Fashion Design 02: Textiles and Fashion. Switzerland: AVA Publishing.

Wang, Y., Qin, S. F., \& Harrison, D. (2013). Culture-inspired design principles, methods and tools in current products. The 5th Intl Congress of the Intl Association of Societies of Design Research, 1-12. Tokyo: Chiba Univrsity. 